\title{
A INFLUÊNCIA DOS TRATADOS AMBIENTAIS MULTILATERAIS RELATIVOS AOS RESÍDUOS NA EFETIVIDADE DO DIREITO AMBIENTAL NO BRASIL
}

\section{RESUMO}

\section{Lauren Lautenschlager ${ }^{1}$}

$\mathrm{O}$ artigo busca analisar a relação entre os tratados ambientais multilaterais relativos aos resíduos e as políticas públicas brasileiras. Parte-se da hipótese de que quanto mais específico o tratado, maior e mais efetiva é a produção normativa-institucional brasileira no mesmo tema. Para tanto, a análise será feita por meio de uma matriz de análise composta por critérios de efetividade os quais serão aplicados tanto nos tratados, quanto nas normas e instituições criadas pelo governo brasileiro. Conclui-se que os textos ambientais internacionais ratificados pelo Brasil exercem grande influência nas políticas públicas ambientais brasileiras.

Palavras-chave: Resíduos; Efetividade; Proteção Ambiental; Políticas Públicas; Internacionalização.

\section{THE INFLUENCE OF MULTILATERAL ENVIRONMENTAL TREATIES RELATED TO WASTE IN THE EFFECTIVENESS OF ENVIRONMENTAL LAW IN BRAZIL}

\begin{abstract}
The article aims to analyze the relationship between multilateral environmental treaties on waste and Brazilian public policies. We hypothesized that the more specific the treaty, the greater and more effective the normative-institutional Brazilian production in the same subject. The analysis will be done through an analysis of a matrix composed by effectiveness criteria that will be applied both in the treaties and in the norms and institutions created by the Brazilian government. we conclude that international environmental texts ratified by Brazil exert a great influence on Brazilian public environmental policies.
\end{abstract}

Keywords: Waste; Effectiveness; Environmental Protection; Public policy; Internationalization.

\section{INTRODUÇÃO}

Este artigo se insere no contexto do que Ayala (2002) denomina por "crise ambiental" que surge como consequência da sociedade da segunda modernidade (BECK, 2009) o que faz com que a questão de proteção ambiental seja tratada como uma questão de sobrevivência (MALJEAN-DUBOIS , 2014) e não como um Estado teatral (BENJAMIN, 2010). Isso porque se faz presente o que Canotilho (2010) menciona como "Estado Socioambiental de Direito".

\footnotetext{
${ }^{1}$ Doutora em Direito pelo Centro Universitário de Brasília. Professora de Direito Internacional da Faculdade Sul Americana de Goiânia. Advogada. E-mail: lauren.lauten@gmail.com.
} 
Vários são os fatores pelos quais a pesquisa se justifica. Dentre eles como aponta Freitas (2019), o aumento populacional, o consumo excessivo, o fato do Brasil ser, conforme WWF (2019) o $4^{\circ}$ maior produtor de lixo plástico do mundo e um dos que menos recicla este tipo de lixo, a proteção internacional "parcial" dada ao assunto, a forma como o Brasil gerencia a questão dos resíduos, os impactos ambientais decorrentes (como por exemplo, contaminação do solo, da água subterrânea e do ar), o risco a saúde pública dos dejetos (decorrentes dos fármacos), e a recente decisão do Supremo Tribunal Federal no que tange a utilidade pública de obras voltadas à gestão de resíduos ${ }^{2}$, o que se torna um problema social, ambiental, econômico exigindo solução tanto da ordem jurídica internacional, quanto da ordem jurídica interna.

O direito ambiental para se tornar uma disciplina jurídica de resultado exige a interdisciplinariedade ${ }^{3}$. Isso porque há relação direta entre a efetividade da proteção ambiental brasileira e o conteúdo dos tratados ambientais multilaterais. Quanto mais específico o tratado nas obrigações a serem atingidas, quanto maiores os esforços e as conquistas dos negociadores internacionais em realizar um texto mais consistente, maior e mais efetiva é a produção normativa brasileira no mesmo tema. Tal relação pode ser observada, tanto com a criação de normas e instituições criadas em decorrência dos documentos internacionais firmados, como pelo resultado da aplicação dos critérios de efetividade.

O objeto deste estudo é analisar a relação entre o conteúdo dos tratados ambientais multilaterais relativos aos resíduos ratificados pelo Brasil e as políticas públicas por este realizadas. Para isso, será estruturada e aplicada uma matriz de análise composta por critérios de efetividade.

\footnotetext{
${ }^{2}$ Vide STF, ADI 4903.

${ }^{3}$ Esta interdisciplinariedade ocorre em relação ao que se pode compreender e como mensurar a efetividade; ocorre quando se busca auxílio da teoria dos regimes (ver YOUNG, O.R. Teoria do regime e a busca de governança global. In: Proteção internacional do meio ambiente. Vol 4. Marcelo D. Varella e Ana Flavia Barros-Platiau (Org.). Brasília: UNITAR, UNICEUB, UNB, 2009, pp. 220-235. Conforme BIRNIE, P. e BOYLE, A. International Law and the environment.2.ed. Oxford, 1994), ou ainda com a aproximação do direito com as políticas públicas. Além disso, é necessário que qualquer investigação ocorra de forma interna e internacional. Dessa forma, dois sub-ramos do direito serão abordados, com todas as suas complexidades inerentes e inter-relações necessárias (ver MORRISON, F.L. The relationship of international, regional, and national environmental law. In: International, Regional, and National Environmental Law. MORRISON, F.L., WOLFRUM, R. (Ed). Kluwer Law International. Springer, 2000, pp. 113-132. Em sentido semelhante, WOLFRUM, R. The convention on biological diversity: using state jurisdiction as a means of ensuring compliance. In: Enforcing environmental standards: Economic mechanisms as viable means? WOLFRUM, R. (Ed.) Springer, 1996, pp. 374-393): o direito internacional ambiental e o direito ambiental doméstico. Trabalhase, assim, com a ideia tanto de internacionalização (ver VARELLA, M. D. Internacionalização do Direito: direito internacional, globalização e complexidade. Brasília: UniCEUB, 2013), como com a ideia de internalização.
} 
Assim, o presente artigo além desta e da conclusão será dividido em três partes. Na primeira, será explicada a matriz de análise. Na segunda, a contextualização e o conjunto de normas e instituições a ser objeto de aplicação da matriz será delimitado. Por fim, na terceira ocorrerá a descrição dos resultados com a aplicação dos critérios.

\section{MATRIZ DE ANÁLISE}

A fim de analisar a relação entre o conteúdo dos tratados ambientais multilaterais ratificados pelo Brasil e relativos aos resíduos, construiu-se uma matriz composta por critérios de efetividade no âmbito global, os quais foram divididos entre materiais e formais e que serão aplicados nos tratados ambientais multilaterais, bem como critérios de efetividade no âmbito nacional, os quais foram divididos entre normativos e institucionais que serão aplicados nas normas e instituições criadas pelo governo brasileiro.

No âmbito global, em relação aos aspectos materiais, um tratado ambiental terá mais chances de ser efetivo se ele: (a) assegurar a proteção ambiental, (b) conduzir à modificação no comportamento humano, (c) tiver impacto só por meio de sua própria existência, (d) possuir clareza no conteúdo das obrigações e (e) dispor de metas e métodos. Já, em relação aos aspectos formais, um tratado ambiental será considerado efetivo para a presente análise, na medida em que ele: (a) tiver entrado em vigor em tempo razoável, (b) contiver formas de garantir a conformidade e (c) contiver meios para promover o cumprimento.

A escolha dos critérios no âmbito nacional utilizou alguns critérios estabelecidos no âmbito global, mas também, substituiu e incluiu outros. As normas feitas pelo Brasil serão efetivas se: (a) tiverem entrado em vigor em tempo razoável (b) corresponderem com os objetivos do tratado ambiental, (c) possuírem clareza no conteúdo das obrigações, (d) disporem de metas e métodos, (e) forem completas, com todas as normas necessárias, (f) conduzirem a modificação no comportamento humano, (g) tiverem impacto só por meio de sua própria existência, (h) contiverem formas de garantir a conformidade e (i) contiverem meios para promover o cumprimento. As instituições serão consideradas efetivas se: (a) forem criadas em tempo razoável, (b) corresponderem com o objetivo das normas criadas, (c) forem completas, com todos os órgãos necessários e (d) tiverem vitalidade institucional. Alguns desses critérios são os mesmos a serem analisados nos arranjos normativos, apenas contextualizados com os arranjos institucionais. 
É importante mencionar que a escolha de critérios deve ser acompanhada pela forma apropriada de ler os critérios. Assim, para tornar o trabalho mais objetivo, os critérios foram exaustivamente trabalhados em estudo específico (VARELLA; LAUTENSCHLAGER, 2016).

Além disso, a aplicação de tais critérios ocorrem em diferentes tipos de normas, uma vez que, normativamente, no âmbito internacional existem Convenções e Protocolos. Já, no âmbito interno, as normas foram divididas em normas internalizantes ${ }^{4}$, específicas ${ }^{5}$ e exequentes $^{6} \mathrm{e}$, institucionalmente, no âmbito interno existem diferentes órgãos como secretarias, departamentos e grupos de trabalho. Por fim, os critérios que compõem a matriz serão interpretados como de aplicação/observação positiva, como de aplicação/observação negativa, como de aplicação/observação parcial, ou ainda, como não aplicados. Todas as normas e instituições a serem analisadas relacionam-se diretamente, com os documentos internacionais firmados e se encontram em vigor.

\section{CONTEXTUALIZAÇÃO E CONJUNTO NORMATIVO-INSTITUCIONAL}

\subsection{No âmbito internacional}

$\mathrm{O}$ comércio internacional de resíduos perigosos é característico do final do século $\mathrm{XX}$ e teve início na década de 70. As suas primeiras movimentações ocorreram entre EUA e Canadá, dentro da Europa Ocidental (França e Inglaterra) e nas Repúblicas Alemãs (a Federal utilizando a Democrática como o seu depósito particular de rejeitos), movimentando conforme menciona Murphy (1994) bilhões de dólares. O processo de discussão sobre a movimentação dos resíduos de produção, iniciado em ocorreu segundo Leão (2006) principalmente, em face dos seguintes fatores: a) aumento das atividades industriais com métodos "sujos" de produção, b) o aumento da consciência ambiental c) recrudescimento das

\footnotetext{
${ }^{4}$ As normas internalizantes referem-se a decretos legislativos e decretos executivos que possuem como finalidade apenas aprovar e promulgar (ou seja, internalizar) os documentos internacionais, fazendo-os valer em território nacional. Como as normas internalizantes trazem apenas a aprovação e/ou promulgação dos documentos internacionais, os únicos critérios que serão aplicados a esse conjunto inicial de normas terão validade se: a) tiverem entrado em vigor em tempo razoável, b) corresponderem aos objetivos do tratado ambiental, e) conduzirem a modificação no comportamento humano e f) tiverem impacto só por meio de sua própria existência. $\mathrm{O}$ teor dessas normas não traz nenhuma obrigação, meta, compliance nem enforcement. Além disso, não exige nenhuma normatização posterior.

${ }^{5}$ As normas específicas referem-se aos atos legislativos primários específicos ao tema objeto no tratado ambiental.

${ }^{6}$ As normas exequentes referem-se aos atos legislativos subsequentes que buscam executar o ato legislativo primário. Fazem parte desse último conjunto, Decretos não numerados, Resoluções, Instruções Normativas e Portaria dos órgãos ambientais.
} 
legislações internas (impondo restrições, aplicando multas e aumentando das exigências - e dos custos - para a disposição de lixo tóxico), d) proibição internacional ao uso das águas dos oceanos como despejo de lixo tóxico, e) crescimento da exportação de lixo perigoso evidenciado nas manchetes, f) manifestações das ONGs.

O ideal para resolver a crise gerada pelo lixo industrial é a produção limpa (clean production). Porém, até que isso ocorra é necessário armazenar e manipular tais materiais de uma forma que não prejudique o meio ambiente.

O arranjo normativo internacional sobre o regime dos resíduos é formado pela Convenção de Basileia sobre o controle do movimento transfronteiriço de resíduos perigosos de 1989 (depois de cinco reuniões preparatórias), a qual teve a Emenda de Proibição adotada na decisão da segunda reunião da Conferência das Partes em 1994, tendo sido admitida uma nova decisão na terceira Reunião da Conferência das Partes realizada em Genebra em 1995. Todavia, nos anos seguintes, houve divergências de opinião entre as Partes quanto à interpretação da disposição sobre emendas à Convenção e, após várias reuniões, sem o acordo a respeito, o Presidente da nona reunião da Conferência das Partes emitiu uma Declaração convidando as Partes a criar condições favoráveis, entre outras medidas, por meio de iniciativas lideradas por países que conduzam à consecução dos objetivos da Emenda. Como resultado, a Indonésia e a Suíça anunciaram a sua disponibilidade para organizar uma "iniciativa liderada pelos países", aprovando, na décima reunião, uma interpretação do nº 5 do artigo $17^{\circ}$ da Convenção de Basileia sobre as alterações à Convenção. Em que pese tenha uma interpretação agora consensual, essa Emenda ainda não entrou em vigor. Em 1998, houve, ademais, uma Emenda ao Anexo I e a Adoção dos Anexos VIII e IX que aconteceu durante a nona reunião ocorrida na Malásia. Essa Emenda já entrou em vigor nos planos internacional e interno.

Além da Convenção, na quinta Conferência das Partes, ocorrida em 1999, foi adotado o Protocolo de Basileia sobre Responsabilidade e Compensação ${ }^{7}$ ainda não entrou em vigor. Por essa razão, o único documento relativo aos resíduos que foi ratificado pelo Brasil foi a

\footnotetext{
7 As conversações do Protocolo começaram em 1993 em resposta às preocupações dos países em desenvolvimento sobre a sua falta de fundos e tecnologias para lidar com o despejo ilegal ou derrames acidentais. Esse documento tem como objetivo estabelecer um regime global de responsabilidade, bem como uma indenização adequada e rápida dos danos resultantes do movimento transfronteiriço de resíduos perigosos e outros resíduos, incluindo os que se verificam devido ao tráfego ilegal desses resíduos. O Protocolo aborda quem é financeiramente responsável no caso de um incidente. Considera-se cada fase de um movimento transfronteiriço, desde o momento em que os resíduos são carregados nos meios de transporte até a sua exportação, trânsito internacional, importação e eliminação final.
} 
Convenção com posterior Emenda adotada durante a nona reunião ocorrida na Malásia em 1998.

A Convenção aborda apenas sobre um tipo de resíduos (perigosos) e uma única forma de controle sobre eles (movimento transfronteiriço), em que pese Smith (1993) destaca a necessidade das normas globais se preocuparem mais com a gestão de resíduos do que com a restrição ao transporte transfronteiriço destes. Além disso, ela sofre críticas por não ter dado enfoque apropriado à questão da reimportação dos rejeitos perigosos, quando eles não forem adequadamente eliminados no País importador. Em relação a isso, é importante mencionar que conforme Machado (2016) o exportador nem sempre é a pessoa mais envolvida pelos rejeitos. A OCDE acredita que o produtor do rejeito é aquele que, além de ter uma maior capacidade financeira, conhece melhor os seus rejeitos e sabe como eliminá-los.

\subsection{No âmbito interno}

Abordar a temática dos resíduos é algo complexo em face da variedade de tipologia ${ }^{8}$ deles, a sua produção, o tratamento e o descarte. De forma geral, a produção de resíduos no Brasil conforme o Plano Nacional de Resíduos Sólidos (2012) tem impacto direto com a exploração e a produção de petróleo e gás, bem como o alto consumo de agrotóxicos. Tal produção não ocorre da mesma forma entre os Estados da federação. A desigualdade na produção leva ao seu tratamento diferenciado e ao seu descarte, o que dificulta traçar um diagnóstico completo da situação dos resíduos.

A Lei 12.305 de 2010 após vinte anos de discussões no Congresso Nacional instituiu a Política Nacional de Resíduos Sólidos - PNRS $^{9}$. Essa Lei integra a PNMA e articula-se com a Política Nacional de Educação Ambiental e com a Política Federal de Saneamento Básico, tendo sido regulamentada pelo Decreto $\mathrm{n}^{\circ}$ 7.404/10. Além de misturar os conceitos de resíduos, é importante mencionar que a Lei específica sobre resíduos sólidos não é completa,

\footnotetext{
${ }^{8}$ A classificação dos resíduos deve observar, dentre outras normas, a Portaria IBAMA no ${ }^{138-N}$ e pela NBR 10004 de 2004 da ABNT.

${ }^{9}$ Antes da PNRS várias normas sobre resíduos sólidos haviam sido feitas, tanto de forma geral como a Portaria MINTER $n^{\circ}$ 53/79, como de forma específica, por exemplo, feitas de acordo com a origem do resíduo (por exemplo: urbano, via Resolução CONAMA n 404/2008, ou industrial, via Resolução CONAMA no 313/2002; gerados nos portos, aeroportos e terminais, via Resolução CONAMA n ${ }^{\circ}$ 358/05; provenientes de estabelecimentos de saúde, via Resolução CONAMA n 006/91 e Resolução nº 283/01; óleos lubrificantes via Resolução CONAMA no 362/05; pilhas e baterias via resolução CONAMA n 401/08; pneus via Resolução CONAMA n 416/09; construção civil via Resolução CONAMA 307/02) ou ainda feitas de acordo com a atividade a ser realizada (por exemplo, transporte de produtos perigosos via Decreto $\mathrm{n}^{\circ} 88.821 / 83$ e Portaria Ministro do Estado e dos Transportes n ${ }^{\circ}$ 204/97, proibição de importação via Resolução CONAMA nº 008/91).
} 
uma vez que, de acordo com o $\S 2^{\circ}$ do seu art. $1^{\circ}$, ela não se aplica aos rejeitos radioativos, os quais são regulados por legislação específica (Lei no 10.308/01). Além disso, ela não é única, pois embora abranja normas sobre resíduos sólidos, devem ser aplicadas, conforme o seu art. $2^{\circ}$, a Lei $n^{\text {o }} 11.445 / 07$, a Lei $n^{\circ} 9.974 / 00$ e a Lei $n^{\circ} 9.966 / 00$, bem como as normas estabelecidas pelos órgãos do Sistema Nacional do Meio Ambiente (Sisnama), do Sistema Nacional de Vigilância Sanitária (SNVS), do Sistema Unificado de Atenção à Sanidade Agropecuária (Suasa) e do Sistema Nacional de Metrologia, Normalização e Qualidade Industrial (Sinmetro). Assim, é possível perceber que o gerenciamento dos resíduos sólidos não se submete a um regime jurídico único como menciona Fiorillo (2013), porquanto varia de acordo com a localidade onde são gerados e com o seu conteúdo e/ou, em outras palavras, de acordo com a sua origem e a sua periculosidade, o que segundo Silva et. al (2016) dificulta a sua gestão.

A Lei $n^{o}$ 12.305/10 não parece ter sido feita em consequência da Convenção da Basileia, uma vez que, mesmo sendo posterior, não faz qualquer referência à referida Convenção, não abordando sobre o comércio de resíduos perigosos. Além disso, possui um conteúdo mais abrangente que aquela, já que apenas alguns de seus dispositivos referem-se aos resíduos perigosos e ao movimento tranfronteiriço. Em que pese se reconheça a relação entre a temática objeto do documento internacional firmado e essa Lei, não há como afirmar que esta tenha ocorrido em decorrência daquele. Por esse motivo e respeitando a delimitação imposta no presente estudo, a Lei n ${ }^{\circ}$ 12.305/10 não será objeto de aplicação de critérios.

Assim, são consideradas normas internalizantes: o Decreto Legislativo $n^{\circ} 34 / 92$, o Decreto $n^{\circ}$ 875/93, relacionados à Convenção da Basileia, e o Decreto legislativo 463/01 e o Decreto $n^{\circ} 4.581 / 03$ relativos à emenda da Convenção que alterou apenas os seus anexos. Não foi identificada nenhuma norma específica. Por fim, como normas exequentes, existem a Portaria IBAMA n ${ }^{\circ} 138-N / 92$, a Resolução CONAMA n ${ }^{\circ} 452 / 12^{10}$ e as Instruções Normativas do IBAMA n ${ }^{\circ} 13 / 12,01 / 13$ e 12/13.

Em relação às Instituições, é importante citar o Comitê Interministerial da PNRS e o Comitê Orientador para Implantação dos sistemas de logística reversa, ambos previstos no Decreto $\mathrm{n}^{\mathrm{o}} 7.404 / 10$, todavia não é possível precisar que tais instituições foram criadas em

\footnotetext{
${ }^{10}$ Tal Resolução é a que se encontra em vigor, mas não é o primeiro documento a cumprir com a Convenção da Basileia. Antes dela, houve as seguintes Resoluções CONAMA n 08/91, 07/94, 37/94, 23/96 (complementada pela Resolução no $228 / 97$ e alterada pelas Resoluções no 235/98 e 244/98).
} 
decorrência da Convenção da Basileia. Por este motivo, não foram encontradas Instituições específicas decorrentes do documento internacional assinado referente aos resíduos.

A Secretaria de Qualidade Ambiental nos Assentamentos Humanos criada pelo Decreto $n^{\circ}$ 2.972/99 era competente para tratar sobre os resíduos danosos à saúde e ao meio ambiente. A periculosidade aos resíduos como competência da Secretaria só ocorreu em 2007, pelo Decreto $\mathrm{n}^{\circ}$ 6.101. Nem mesmo a nova estrutura do MMA, estabelecida pelo Decreto $\mathrm{n}^{\circ}$ 8.975/17, dispõe de órgão específico aos resíduos. A gestão de resíduos faz parte do Departamento de Qualidade Ambiental que integra a Secretaria de Recursos Hídricos e Qualidade Ambiental. A essa Secretaria compete a gestão e o gerenciamento de resíduos sólidos, incluídos os resíduos perigosos.

\section{DESCRIÇÃO DOS RESULTADO DA APLICAÇÃO DA MATRIZ}

\subsection{Do conjunto normativo internacional}

Analisando a Convenção de Basileia sobre o controle do movimento transfronteiriço de resíduos perigosos e o seu depósito, fez-se possível observar que, dos oito critérios (cinco de natureza material e três de natureza formal), cinco deles tiveram aplicação positiva (três de natureza material e dois de natureza formal) e três deles (dois de natureza material e um de natureza formal) tiveram aplicação parcial.

Com relação aos critérios que tiveram aplicação positiva, pode-se afirmar que, materialmente, a Convenção assegura a proteção ambiental na medida em que a proteção ocorre via controle rigoroso dos efeitos nocivos que podem resultar da produção e gestão de resíduos. Esse mesmo controle demonstra que ela conduz à modificação do comportamento humano, já que incentiva a gestão ambientalmente segura e racional e a redução do volume do movimento transfronteiriço. Os impactos derivados por sua própria existência podem ser vistos tanto juridicamente, seja pela criação da Conferência das partes (art.15º, seja ainda porque protocolos podem ser feitos, quando extra juridicamente, na medida em que sinaliza para a comunidade internacional que os Estados Partes que assinaram o documento preocupam-se com tal tema. Formalmente, a Convenção entrou em vigor em tempo razoável, já que, elaborada em 1989, entrou em vigor três anos após, em 1992. Os meios para promover o cumprimento ocorrem por meio dos mecanismos de resolução de conflitos previstos no art. $20^{\circ}$ e do procedimento de arbitragem previsto no anexo VI. 
Os critérios materiais que tiveram aplicação parcial são os relacionados às obrigações e às metas. Como obrigações claras, podem ser citadas as obrigações de a) informar o secretariado e de transmitir as informações, que se acha prevista no art. $3^{\text {o}}$; informar a decisão prevista no art. $4^{\circ}, \S 1^{\circ}$; b) Não permitir exportação e importação a não partes prevista no art. $\left.4^{\mathrm{o}}, \S 5^{\mathrm{o}} ; \mathrm{c}\right)$ Proibir todas as pessoas sob a sua jurisdição nacional de transportar ou eliminar resíduos perigosos ou outros resíduos, exigir que os resíduos sejam embalados, rotulados e transportados em conformidade com as regras e os padrões estabelecidos e exigir que os resíduos sejam acompanhados da documentação devida prevista no art. $4^{\circ}, \S 7^{\circ}$; d) Exigir que os resíduos perigosos e outros resíduos a ser exportados sejam geridos de uma forma ambientalmente segura e racional no Estado importador ou em outro qualquer lugar contida no art. $4^{\circ}, \S 8^{\circ}$; e) Rever periodicamente as possibilidades de redução do volume e/ou da poluição potencial dos resíduos perigosos ou de outros resíduos que são exportados para outros Estados, prevista no art. $4^{\mathrm{o}}, \S 13^{\circ}$; f) Designar autoridades competentes prevista no art. $5^{\mathrm{o}}$; possibilitar o movimento transfronteiriço entre as Partes previstas no art. $6^{\mathrm{o}} ; \mathrm{g}$ ) Possibilitar o movimento transfronteiriço a partir de uma Parte e por intermédio de Estados que não são Partes previstas no art. $7^{\text {o }}$; reimportar prevista no art. $8^{\circ} ;$ h) Assegurar que os resíduos trafegados ilicitamente sejam devolvidos ou eliminados, prevista no art. $9^{\circ}, \S 2^{\circ}$; i) Assegurar que os resíduos em questão são eliminados de uma forma ambientalmente segura e racional, pelo importador ou eliminador ou, se necessário, por ele mesmo, prevista no art. $9^{\circ}, \S 3^{\circ}$ (primeira parte); j) ooperar na eliminação dos resíduos perigosos de uma forma ambientalmente segura e racional prevista no art. $9^{\circ}, \S 3^{\circ}$ (segunda parte), $\S 4^{\circ}$ e $\S 5^{\circ} ; \mathrm{k}$ ) Cooperar a fim de melhorar e obter uma gestão ambientalmente segura e racional de resíduo prevista no art. $10^{\circ}$; 1) Cooperar com vistas a adoptar um protocolo sobre responsabilidade e compensação por danos resultantes do movimento transfronteiriço e eliminação de resíduos perigosos e de outros resíduos prevista no art. $12^{\circ}$ e m) Transmitir informações e enviar relatórios prevista no art. $13^{\circ}$. Todavia, consideram-se obrigações não claras as obrigações de: tomar medidas necessárias previstas no art. $4^{\circ}, \S 2^{\circ}$, tomar medidas para implementar e reforçar as condições dessa Convenção prevista no art. $4^{\circ}, \S 4^{\circ}$ e de tomar as medidas necessárias para assegurar que o movimento transfronteiriço de resíduos seja permitido prevista no art. $4^{\circ}, \S 9^{\circ}$, uma vez que são vagas. Por fim, as metas consideradas claras referem-se à meta de cooperar para melhorar a correta gestão ambiental de tais resíduos e conseguir a prevenção do tráfego ilícito, prevista no art. $4^{\circ}, \S 2^{\circ}$, "h" e a meta de cooperar a 
fim de melhorar e obter uma gestão ambientalmente segura e racional de resíduo prevista no art. $10^{\circ}$. Por seu turno, as metas que não dispõem de método não sendo claras referem-se à meta de assegurar que a produção de resíduos seja reduzida prevista no art. $4^{\circ}, \S 2^{\circ}$ "a"; à meta de cooperar na eliminação dos resíduos perigosos de uma forma ambientalmente segura e racional prevista no art. $9^{\circ}, \S 3^{\circ}$ (segunda parte), $\S 4^{\circ}$ e $\S 5^{\circ}$; à meta de exigir que os resíduos perigosos e outros resíduos a serem exportados sejam geridos de uma forma ambientalmente segura e racional no Estado importador ou em outro qualquer lugar prevista no art. $4^{\circ}, \S 8^{\circ}$ e à meta de cooperar com vista a adotar um protocolo sobre responsabilidade e compensação por danos resultantes do movimento transfronteiriço e eliminação de resíduos perigosos e de outros resíduos prevista no art. $12^{\circ}$.

O critério formal que teve aplicação parcial foi o de conter formas de garantir a conformidade, haja vista que, embora exista o envio de relatórios previsto no art. $13^{\circ}, \S 3^{\circ}$, a avaliação da efetividade conforme dispõe o art. $15^{\circ}, \S 7^{\circ}$ e a verificação de uma parte a outra em relação às infrações, às obrigações dessa Convenção conforme art. $19^{\circ}$, nada foi decidido a respeito dos mecanismos financeiros previstos no art. $14^{\circ}$.

A fim de proporcionar uma melhor visualização da aplicação dos critérios de efetividade no documento internacional relacionado aos resíduos, segue quadro:

\begin{tabular}{|l|l|l|}
\hline & CRITÉRIOS & CONVENÇÃO \\
\hline \multirow{4}{*}{ MATERIAL } & Assegurar a proteção ambiental & Positivo \\
\cline { 2 - 3 } & Conduzir à modificação no comportamento humano & Positivo \\
\cline { 2 - 3 } & Tiver impacto só por meio de sua própria existência & Positivo \\
\cline { 2 - 3 } & Possuir clareza no conteúdo das obrigações & Parcial \\
\cline { 2 - 3 } & Dispor de metas e métodos & Parcial \\
\hline \multirow{3}{*}{ FORMAL } & Tiver entrado em vigor em tempo razoável & Positivo \\
\cline { 2 - 3 } & Contiver formas de garantir a conformidade (compliance) & Parcial \\
\cline { 2 - 3 } & $\begin{array}{l}\text { Contiver meios para promover o cumprimento } \\
(\text { enforcement })\end{array}$ & Positivo \\
\hline
\end{tabular}

\subsection{Do conjunto normativo-institucional doméstico}

Três critérios das normas internalizantes tiveram aplicação positiva. Eles referem-se à correspondência com os objetivos do tratado ambiental, à condução à modificação no comportamento humano e a terem impacto só por meio de sua própria existência. 
Apenas um deles teve aplicação parcial, qual seja o critério da entrada em vigor em tempo razoável, que, como já mencionado, é analisado de forma diferente quando se trata de Decreto Legislativo ou Decreto presidencial. Os Decretos Legislativos no 34/92, 463/01 e o Decreto presidencial $n^{\circ} 875 / 93$ foram positivos a esse critério entrando em vigor em tempo razoável, o que não ocorreu com o Decreto presidencial no 4.581/03.

Dos quatro critérios das normas exequentes, três critérios tiveram aplicação positiva. Eles referem-se à correspondência com os objetivos do tratado ambiental, à condução à modificação no comportamento humano e a terem impacto só por meio de sua própria existência.

A Portaria no 139/92 teve correspondência, na medida em que pró́be a importação de resíduos, excetuando os constantes no anexo I de acordo com a necessidade de matéria-prima; a Resolução $n^{\circ} 452 / 12$ porque dispõe sobre os procedimentos de controle da importação de resíduos; a Instrução Normativa o 13/12, uma vez que, ao publicar a Lista Brasileira de Resíduos Sólidos, padroniza a linguagem utilizada para a prestação de informações sobre resíduos sólidos. Ademais, a Instrução Normativa $n^{\circ}$ 01/13, pois regulamenta o Cadastro Nacional de Operadores de Resíduos Perigosos (CNORP), estabelece a sua integração com o Cadastro Técnico Federal de Atividades Potencialmente Poluidoras ou Utilizadoras de Recursos Ambientais (CTF-APP) e com o Cadastro Técnico Federal de Atividades e Instrumentos de Defesa Ambiental (CTF-AIDA), bem como define os procedimentos administrativos relacionados ao cadastramento e à prestação de informações sobre resíduos sólidos, inclusive os rejeitos e os considerados perigosos e a Instrução Normativa $n^{\circ}$ 12/13, na medida em que dispõe sobre a regulamentação dos procedimentos de controle da importação de resíduos.

A condução na modificação do comportamento humano fez-se presente na Portaria $\mathrm{n}^{\circ}$ 139/92 na medida em que proíbe, como regra, a importação de resíduos; na Resolução no 452/12, já que dispõe sobre os procedimentos de controle da importação de resíduos; na Instrução Normativa $\mathrm{n}^{\circ}$ 13/12, pois a padronização da linguagem é o primeiro passo para permitir e facilitar o monitoramento, o controle, a fiscalização e a avaliação da eficiência da gestão e do gerenciamento de resíduos sólidos nos diversos níveis; na Instrução Normativa ${ }^{\circ}$ 01/13, exigindo a inscrição no CNORP das pessoas jurídicas que exerçam atividades de geração e operação de resíduos perigosos e na Instrução Normativa no 12/13 já que traz, em 
seu anexo, a listagem dos resíduos, cuja importação é proibida e aqueles cuja importação é controlada.

O critério dispor de metas e métodos foi observado de forma negativa, em face da inexistência de metas específicas nesse conjunto de normas.

Os demais critérios tiveram aplicação parcial, conforme se apresenta na sequência.

O critério sobre tiverem entrado em vigor em tempo razoável foi observado de forma negativa nas Instruções Normativas $n^{\circ}$ 13/12 e 01/13 relacionadas com a data de elaboração da Convenção. A Portaria 139/92 não foi a primeira a regulamentar sobre importação de resíduos. Isso ocorreu no ano 1990, via Portaria $\mathrm{n}^{\circ} 1.197$, portanto, entrando em vigor em tempo razoável, se relacionada com a data da elaboração da Convenção. O mesmo ocorreu com a Resolução $n^{\circ} 452 / 12$, que também não foi a primeira a disciplinar sobre procedimentos de controle da importação de resíduos, uma vez que a primeira Resolução, a de $n^{\circ} 08$, foi feita ainda em 1991, entrando em vigor em tempo razoável, relacionada com a data de elaboração da Convenção. A Instrução Normativa no 12/13 também entrou em vigor em tempo razoável, uma vez que foi relacionada com a Resolução nº 452/12.

O critério sobre completude não pode ser aplicado na Portaria $\mathrm{n}^{\circ} 139 / 92$, nem mesmo nas Instruções Normativas $n^{\circ} 13 / 12,01 / 13,12 / 13$, pois elas já figuram como norma final. Na Resolução $n^{o} 452 / 12$, tal critério foi observado de forma positiva porque a Instrução Normativa, que deveria ser feita, corresponde à Instrução Normativa de $n^{\circ} 12 / 13$, embora tenha entrado em vigor de forma atrasada já que a Resolução $n^{\circ}$ 452/12 exigia a publicação de uma Instrução em até 180 dias.

O critério sobre possuir clareza no conteúdo das obrigações não pode ser aplicado na Instrução Normativa $n^{\circ}$ 13/12, já que ela apenas publicou a Lista Brasileira de Resíduos Sólidos, a qual será utilizada pelo Cadastro Técnico Federal de Atividades Potencialmente Poluidoras ou Utilizadoras de Recursos Ambientais, pelo Cadastro Técnico Federal de Atividades e Instrumentos de Defesa Ambiental e pelo Cadastro Nacional de Operadores de Resíduos Perigosos, bem como por futuros sistemas informatizados do IBAMA que possam vir a tratar de resíduos sólidos. Todavia, teve aplicação positiva na IN n $12 / 13$, pois, embora contenha normas de natureza cogente como a proibição de importação de alguns resíduos prevista no art. $3^{\circ}$ ou normas de natureza facultativas, como a possibilidade do IBAMA realizar vistoria e fiscalização de cargas de resíduos importados prevista no art. $10^{\circ}$, ela menciona a obrigação de solicitar autorização de importação ao IBAMA prevista no art. $5^{\circ}$, 
sendo considerada clara; a obrigação do IBAMA emitir autorização prevista no art. $6^{\circ}$ é clara; a obrigação de o importador informar dados, quando do registro de Licença no Sistema Integrado de Comércio Exterior - Siscomex e no sítio do IBAMA prevista no art. $8^{\circ}$ é clara.

$\mathrm{Na} \mathrm{IN} \mathrm{n}^{\mathrm{o}}$ 01/13, a obrigação de inscrição das pessoas jurídicas que exercem atividades de geração e operação de resíduos perigosos no Cadastro Nacional de Operadores de Resíduos Perigosos (CNORP) prevista no art. $3^{\circ}$ é clara. Da mesma forma, ocorreu com a Portaria $\mathrm{n}^{\circ}$ 139/92, por exemplo, no que tange às obrigações referentes às empresas importadoras de resíduos para que elas efetuem o cadastro, atendam à melhor técnica e às normas de acondicionamento e transporte, assim como observem cuidados especiais de manuseio em trânsito, inclusive interno, além de preverem as ações de emergência para cada resíduo, atender às condições estabelecidas pelas legislações de controle ambiental, quanto à armazenagem, à manipulação, à utilização e ao processamento do resíduo importado, bem como de eventuais resíduos gerados nessa operação, inclusive, quanto à sua disposição final, prevista no art. $4^{\circ}$. Além disso, as obrigações para as empresas que pretendem importar, tais como atender os incisos I e II do art. $40^{\circ}$ da norma e informar à empresa que processará o resíduo, previstos no art. $5^{\circ}$, também são claras. Outra obrigação clara é a de apresentar a previsão de importação de resíduos para o ano seguinte, conforme dispõe o art. $9^{\circ}$.

A Resolução n 452/12 que, embora contenha, em sua maioria, artigos de natureza dispositiva e facultativa, traz obrigações claras, como a necessidade de elaboração e publicação da lista de resíduos cuja importação é proibida ou controlada com base na Nomenclatura Comum do Mercosul-NCM, conforme previsão do art. $5^{\circ}$; e a obrigação dos órgãos ambientais comunicarem a ocorrência quando constatarem o descumprimento das condições estabelecidas pela legislação de controle ambiental pertinentes à armazenagem, ao transporte, à manipulação, à utilização e à reciclagem do resíduo importado como prevista no

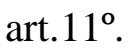

O critério sobre as formas de garantir a conformidade foi observado de forma negativa na Portaria no 139/92, na Resolução no 452/12 e nas Instruções Normativas no 13/12 e 01/13, sendo encontrado de forma positiva na Instrução Normativa 12/13. As formas encontradas versam sobre: a) revisão da autorização de importação sempre que as informações ou os documentos apresentados para a emissão da autorização sofram qualquer alteração ou atualização, devendo ser imediatamente comunicadas ao IBAMA, sob pena de cancelamento ou suspensão da autorização $\left(\operatorname{art} .6^{\circ}, \S 2^{\circ}\right)$; cancelamento ou suspensão da autorização de 
importação, caso constatado o descumprimento de condicionantes específicas (art. $7^{\circ}$ ) ou ainda se constatado, a qualquer tempo, o descumprimento das normas que disciplinam a importação de resíduos, a omissão ou a falsidade de informações que subsidiaram o ato autorizativo, ou nos casos de grave risco ambiental ou à saúde pública $\left(\operatorname{art} .7^{\circ}, \S 2^{\circ}\right)$.

Por fim, o critério sobre meios para promover o cumprimento foi encontrado de forma negativa na Instrução Normativa $n^{0} 13 / 12$. De forma positiva, esse critério aparece como penalidades na Resolução no 139/92 ( $\operatorname{art.11}^{\circ}$ ), na Resolução no 452/12 (art.13º), na Instrução Normativa $n^{\circ} 01 / 13\left(\operatorname{art}^{\circ} 12^{\circ}\right.$ e $14^{\circ}$ ) e na Instrução Normativa ${ }^{\circ} 12 / 13$ (art. 13º).

A fim de proporcionar uma melhor visualização acerca das aplicações dos critérios de efetividade, segue um quadro:

\begin{tabular}{|c|c|c|c|}
\hline & CRITÉRIOS & INTERNALIZANTES & EXEQUENTES \\
\hline & $\begin{array}{l}\text { Entrada em vigor em tempo } \\
\text { razoável }\end{array}$ & Parcial & Parcial \\
\hline & $\begin{array}{l}\text { Correspondência com objetivo } \\
\text { dos tratados }\end{array}$ & Positivo & Positivo \\
\hline & $\begin{array}{l}\text { Clareza no conteúdo das } \\
\text { obrigações }\end{array}$ & $\begin{array}{l}\text { Não existente nesse } \\
\text { conjunto de normas }\end{array}$ & Parcial \\
\hline & Dispor de metas e métodos & $\begin{array}{l}\text { Não existente nesse } \\
\text { conjunto de normas }\end{array}$ & Negativo \\
\hline NORMATIVO & Completude & $\begin{array}{l}\text { Não existente nesse } \\
\text { conjunto de normas }\end{array}$ & Parcial \\
\hline & $\begin{array}{l}\text { Conduzir à modificação no } \\
\text { comportamento humano }\end{array}$ & Positivo & Positivo \\
\hline & $\begin{array}{l}\text { Tiver impacto só por meio de sua } \\
\text { própria existência }\end{array}$ & Positivo & Positivo \\
\hline & $\begin{array}{l}\text { Contiverem formas de garantir a } \\
\text { conformidade }\end{array}$ & $\begin{array}{l}\text { Não existente nesse } \\
\text { conjunto de normas }\end{array}$ & Parcial \\
\hline & $\begin{array}{ll}\text { Contiverem meios para } \\
\text { promover o cumprimento }\end{array}$ & $\begin{array}{l}\text { Não existente nesse } \\
\text { conjunto de normas }\end{array}$ & Parcial \\
\hline
\end{tabular}




\section{CONSIDERAÇÕES GERAIS}

O Direito Ambiental como um todo exige uma pausa reflexiva nunca feita. A relação direta entre o que é estabelecido na seara internacional e o que é feito na seara interna precisa ser ajustada. Tal postura ocorre porque a "ordem pública ambiental" não é admitida na modalidade "incompleta" (LEFF, 2009), ou seja, é preciso que ela integre o paradigma da normatividade efetiva.

O único tratado ambiental multilateral referente aos resíduos abarca apenas um tipo de resíduo e uma atividade referente a este. Isso leva a falta de um ordenamento jurídico doméstico sólido no Brasil. Isso acontece de forma diferente em outras áreas como no clima ${ }^{11}$ e na biodiversidade ${ }^{12}$. De qualquer maneira, a relação entre o direito internacional e o direito interno é estabelecida, seja pela presença do tratado ambiental, seja ainda pela ausência. Com isso, não se quer afirmar que o Brasil depende única e exclusivamente do direito internacional para elaborar normas ou criar instituições, ou ainda que elas não existiam antes mesmo dos documentos firmados, mas, respeitando as delimitações deste estudo, foram analisadas as normas e as instituições criadas em decorrência dos tratados ambientais relativos aos resíduos e, nesse sentido, havendo tratado ambiental vincultativo e abrangente sobre o tema, o qual contenha obrigações claras aos Estados Partes, maior e mais efetiva será a produção normativa-institucional brasileira no mesmo tema. Tal relação versa sobre a quantidade entre normas e instituições criadas, a aplicação dos critérios e o teor das obrigações nas normas internacionais e internas.

Nas normas internalizantes, três critérios mostraram-se positivos (correspondência, condução e impacto). Não foi encontrada nenhuma norma específica, nem mesmo alguma Instituição decorrente dos documentos internacionais relacionados aos resíduos. Em relação às normas exequentes, três critérios foram observados positivamente (correspondência, condução e impacto) e um deles foi observado de forma negativa (metas), em face da inexistência de metas específicas. Os cinco demais critérios foram observados de forma parcial.

\footnotetext{
${ }^{11}$ Vide LAUTENSCHLAGER, L.; VARELLA, M.D. A influência dos tratados ambientais multilaterais relativos ao clima na efetividade do direito ambiental brasileiro. In: Revista Eletrônica do Curso de Direito da UFSM, v.13, p.722-753, 2018.

${ }^{12}$ Vide LAUTENSCHLAGER, L.; VARELLA, M.D. A influência dos tratados ambientais multilaterais relativos à biodiversidade na efetividade do direito ambiental no Brasil. In: Revista Brasileira de Direito IMED, v.14, p.113, 2018.
} 
De forma geral, foi possível perceber um atraso na internalização da emenda da Convenção da Basileia.

As normas exequentes versam sobre a importação dos resíduos, a elaboração da Lista Brasileira de Resíduos Sólidos e da regulamentação do Cadastro Nacional de Operadores de Resíduos Perigosos (CNORP), sendo possível estabelecer algumas relações com as obrigações claras previstas na Convenção.

Relacionando as obrigações claras da Convenção com a disposição das normas exequentes, é importante mencionar que a obrigação da Convenção prevista no art. $4^{\circ} \S 5^{\circ}$ que versa sobre não permitir exportação e importação a não partes foi cumprida por meio da Resolução $n^{\circ}$ 07/94. Essa norma, todavia, não está mais em vigor, estando a proibição da importação prevista na IN $n^{\circ} 12 / 13$. Todavia, o parágrafo $\S 1^{\circ}$ dessa IN esclarece que existe exceção aos casos previstos em acordos bilaterais firmados pelo Brasil, o que pode levar a questionamentos, já que não fica claro que tais acordos devem também ser partes da Convenção. A obrigação da Convenção referente ao transporte e à gestão ambientalmente segura e racional vai ao encontro das metas de cooperação previstas no art. $10^{\circ}$, as quais dispõem de métodos que se coadunam à Portaria $n^{\mathbf{o}}$ 139/92, no que tange às obrigações referentes às empresas importadoras de resíduos para que elas atendam à melhor técnica e às normas de acondicionamento e transporte, assim como observem cuidados especiais de manuseio em trânsito, além de considerarem as condições estabelecidas pelas legislações de controle ambiental, quanto à armazenagem, à manipulação, à utilização e ao processamento do resíduo importado, bem como de eventuais resíduos gerados nessa operação, inclusive, quanto à sua disposição final. Além disso, a Lista Brasileira de Resíduos Sólidos que ocorreu via IN no 13/12; a obrigação de o importador informar dados, quando do registro de Licença no Sistema Integrado de Comércio Exterior - Siscomex e no sítio do IBAMA prevista no art. $8^{\circ}$ da IN no $12 / 13$ e a regulamentação do Cadastro Nacional de Operadores de Resíduos Perigosos (CNORP) que ocorreu via IN n $n^{\circ}$ 01/13 atendem à padronização da linguagem para facilitar o intercâmbio de informações no âmbito da Convenção.

$\mathrm{Na}$ maioria, as normas exequentes entraram em vigor de forma tardia. Por mais que a IN n ${ }^{\circ} 12 / 13$ tenha sido feita em tempo razoável, pois foi relacionada à Resolução 452/12, ela ocorreu fora do prazo, já que o texto da Resolução mencionava que a IN deveria ter sido publicada em até 180 dias. O atraso na elaboração de Instrução Normativa gera um aumento de poder discricionário ao órgão, conforme pode se ver no art.11, que menciona que a 
importação de resíduos cujo embarque tenha ocorrido após a publicação da Resolução Conama $n^{\circ} 452 / 12$ e cujo processo de despacho aduaneiro não tenha sido concluído até a data de publicação dessa Instrução Normativa, deve ser analisado e decidido caso a caso pelo IBAMA.

Além disso, as normas exequentes correspondem aos objetivos do tratado; quando existem obrigações, elas são claras; conduzem à modificação do comportamento humano e produzem impactos. A maioria delas são normas finais, não exigindo nenhum tipo de complementação e apresenta a sujeição a penalidades em caso de descumprimento. Apenas uma norma traz uma forma de promover o cumprimento, a qual menciona que a autorização de importação pode ser revista, suspensa ou cancelada, embora de forma geral, esta seja uma medida comum nos atos administrativos ambientais.

Diferentemente do que ocorre nos demais subsistemas do Direito Internacional, em que as normas operam de forma independente e no movimento de fora para dentro, no direito ambiental internacional, parece haver uma maior importância na determinação de normas internas, tendo em vista o que foi decidido internacionalmente. Com isso, é possível afirmar que os tratados multilaterais ambientais são efetivos, porque induzem, de forma concreta, a produção de normas obrigatórias e a criação de Instituições no Brasil. Dessa forma, o texto de um documento internacional não pode ser considerado como um mero instrumento retórico, pois interfere diretamente na elaboração e na execução das políticas públicas ambientais brasileiras.

\section{REFERÊNCIAS BIBLIOGRÁFICAS}

AYALA, P. A. Direito e incerteza: a proteção jurídica das futuras gerações no Estado de direito ambiental. Dissertação (Mestrado em Direito) Universidade Federal de Santa Catarina. Florianópolis: UFSC, 2002.

BECK, U. La sociedad del riesgo global.Madrid: Siglo Veintiuno, 2002.

BENJAMIN, A.H. O Estado teatral e a implementação do direito ambiental.BDJur, Brasília, DF, 7 maio de 2010.

CANOTILHO, J. J. G. Estado constitucional ecológico e democracia sustentada. In: LEITE, José Rubens Morato, Heline Silvini Ferreira e Larissa Verri Boratti (Orgs.). Estado de direito ambiental: tendências.2.ed. Rio de Janeiro: Forense Universitária, 2010, pp. 31-34. 
FIORILLO, C.A.P. Curso de direito ambiental brasileiro.14.ed. São Paulo: Saraiva, 2013.

FREITAS, V. P. É preciso maior atenção ao problema da destinação dos resíduos. In: Conjur, 2019. Disponível em: https://www.conjur.com.br/2019-mar-03/segunda-leitura-precisomaior-atencao-problema-residuos. Acessado em 20 Mar.2019

LEÃO, M.B.C. Sociedade civil e meio ambiente internacional: o papel das ONGS no desenvolvimento do DIMA - Direito Internacional de Meio Ambiente. In: NASSER, S.H e REI, F. (Org). Direito internacional do meio ambiente. São Paulo: Atlas, 2006, pp. 68 a 88

LEFF, E. Complexidade, Racionalidade Ambiental e Diálogo de Saberes. In: Revista Educação e Realidade. V.34 n.3, p. 17-24, set/dez 2009.

MALJEAN-DUBOIS, S. International environmental law. Seminário Jurídico Avançado realizado no UNICEUB, Brasília, 2014.

MURPHY, S. D. Prospective liability regimes for the transboundary movement of hazardous wastes. In: The American Journal of International Law, v. 88, n. 1, p. 24-75, 1994.

MMA - Ministério do Meio Ambiente. Plano Nacional De Resíduos Sólidos, 2012.

Disponível em:

http://sinir.gov.br/web/guest/plano-nacional-de-residuos-solidos. Acessado em 10 Set.2016.

VARELLA, M.D.; LAUTENSCHLAGER, L. Critérios de Efetividade na Proteção Ambiental. In: Revista do Programa de Pós-Graduação em Direito da UFC, v. 36.1, pp. 295329, jan./jun. 2016.

SILVA, A.R.; CHAVES, G.L.D.; GHISOLF, V. Os obstáculos para uma efetiva política de gestão dos resíduos sólidos no Brasil. Revista Veredas do Direito, v. 13, n. 26, p. 211-234, mai./ ago. 2016. Disponível em: <http://www.domhelder.edu.br/revista/index.

php/veredas/article/view/691>. Acesso em: 10. Jan. 2017.

SMITH, J. T. II. The Challenges of Environmentally Sound and Efficient Regulation of Waste-The Need for Enhanced International Understanding. In: Journal Environmental Law, v. 5 , p. 91, 1993.

WWF. Relatório Solucionar a poluição plástica: transparência e responsabilização, 2019. Disponível em: http://promo.wwf.org.br/solucionar-a-poluicao-plastica-transparencia-eresponsabilizacao. Acesso em 03. Abr. 2019. 